\title{
O Corpo em uma Perspectiva Fenomenológico-Existencial: Aproximações entre Heidegger e Merleau-Ponty ${ }^{1}$
}

\section{The Body In An Existential-Phenomenological Perspective: Approximations Between Merleau-Ponty And Heidegger \\ El Cuerpo En Una Perspectiva Fenomenológico-Existencial: Acercamientos Entre Heidegger Y Merleau-Ponty}
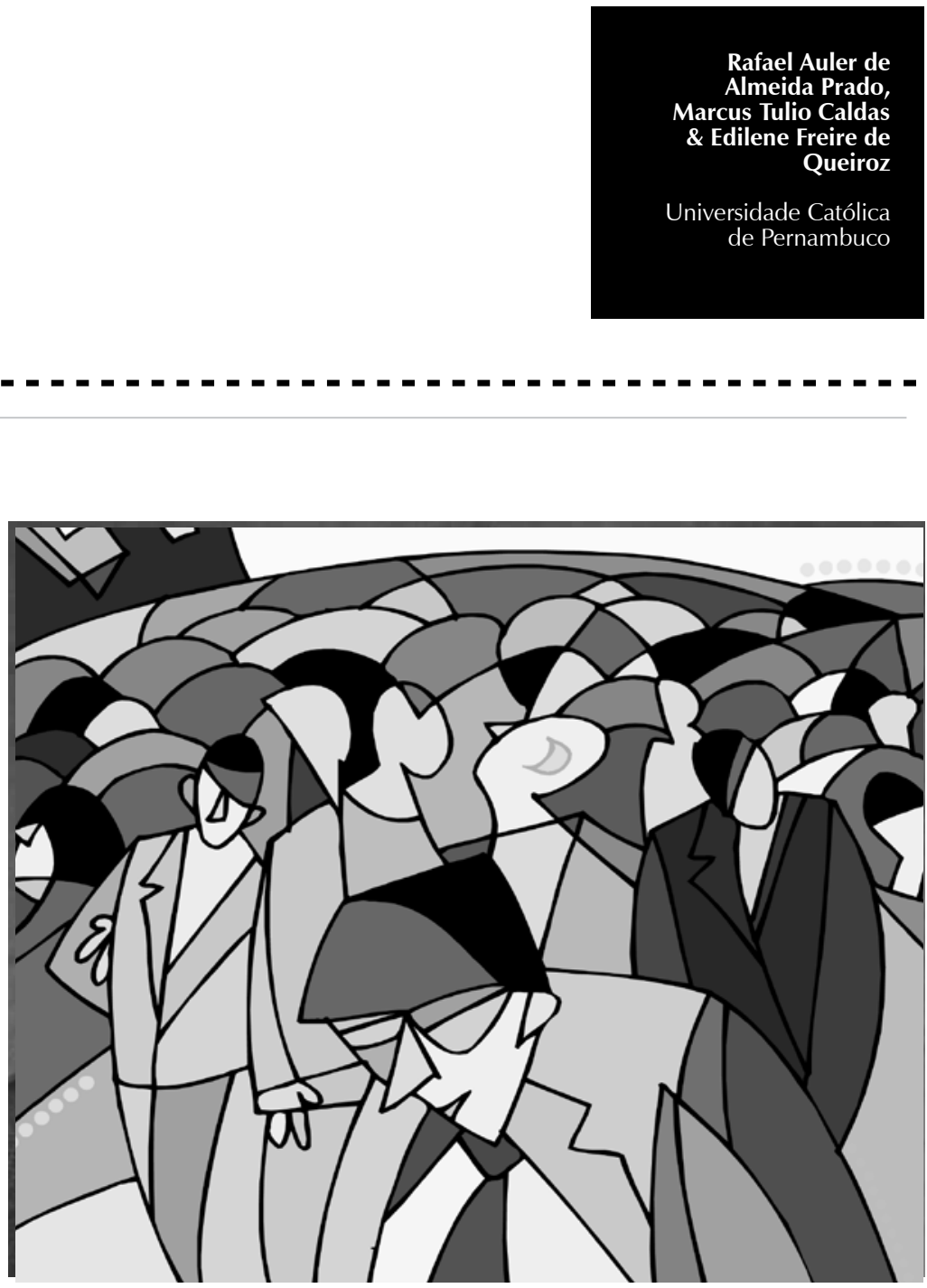
Resumo: Nosso objetivo é pensar sobre o corpo em uma perspectiva fenomenológico-existencial, tomando Heidegger e Merleau-Ponty como referência. Nas concepções tradicionais, tem-se compreendido o corpo como mecanismo biológico, contraposto a uma instância suprassensível (razão, psique ou alma), como fonte de prazer erótico e impessoal e, mais contemporaneamente, como cartão de visita submetido aos ditames da moda, da saúde e da boa forma. Seriam essas concepções absolutas ou expressão de determinado modo de ser da sociedade contemporânea? Que implicações têm tais concepções? Haveria algo impensado? A princípio - consideramos -, há muito que se pensar sobre o corpo sob diversos ângulos temáticos e teóricos, e tanto tais concepções tradicionais quanto as atuais são expressões de um modo de pensar de determinada época. Fazendo uma reflexão respaldada no pensamento heideggeriano, procuramos mostrar um dos caminhos possíveis de se repensar o corpo, procedendo a algumas aproximações com o pensamento de Merleau-Ponty. Veremos como a concepção atual de corpo se vincula a determinada concepção de homem e de ser e que temos uma espécie de intimidade original com o mundo que o olhar sobre o corpo aponta. Tal intimidade deve ser recuperada para cultivarmos um modo mais humano e mais próximo com os outros. Palavras-chave: Corpo. Contemporaneidade. Fenomenologia existencial. Ser.

Abstract: This essay presents an existential-phenomenological perspective of the body, having Heidegger and Merleau-Ponty as reference authors. In the traditional conceptions, the body has been understood as a biological mechanism in opposition to a supersensible instance (ration, mind or soul), as source of erotic and impersonal pleasure, and most recently, as a 'visit card', submitted to fashion, health and good shape tendencies. Would those conceptions be absolute or expression of a certain way of life of the contemporaneous society? Which implications do those conceptions have? Would there be something still unthought? In the first place - we think - there is a lot to consider about the body under theoretical and thematic obliquities. Reflecting on this based on the heideggerian view, this essay intents to show one of the possible ways to rethink the body, according to some approximations to Merleau-Ponty's view. We will see how the present body conception is linked to a certain conception of man and being and that we have a kind of "original intimacy" with the world that the body conception defended in this essay points out. We should recover this intimacy in order to raise a more human, close and intimate way of being in the world and with other people.

Keywords: Body. Contemporary time. Existential phenomenology. Being.

Resumen: Nuestro objetivo es pensar sobre el cuerpo desde una perspectiva fenomenológico-existencial, tomando Heidegger y Merleau-Ponty como referencia. En las concepciones tradicionales, se ha comprendido el cuerpo como mecanismo biológico, contrapuesta a una instancia suprasensible (razón, psiquis o alma), como fuente de placer erótico e impersonal y, más contemporáneamente, como tarjeta de visita sometido a los dictámenes de la moda, de la salud y de la buena forma. ¿Serían ésas concepciones absolutas o una expresión de determinado modo de ser de la sociedad contemporánea? ¿Qué implicaciones conllevan dichas concepciones? ¿Habría algo impensado? A principio - consideramos -, hay mucho qué pensar sobre el cuerpo desde diversos ángulos temáticos y teóricos, y tanto dichas concepciones tradicionales como las actuales son expresiones de un modo de pensar de determinada época. Haciendo una reflexión respaldada en el pensamiento heideggeriano, buscamos mostrar uno de los caminos posibles de repensarse el cuerpo, procediendo a algunos acercamientos con el pensamiento de Merleau-Ponty. Veremos cómo la concepción actual de cuerpo se vincula a determinada concepción de hombre y de ser y que tenemos una especie de intimidad original con el mundo que la mirada sobre el cuerpo señala. Dicha intimidad debe ser recuperada para que cultivemos una forma más humana y más cercana con los demás.

Palabras clave: Cuerpo. Contemporaneidad. Fenomenología existencial. Ser.

1 Agradecemos ao Fundo de Amparo à Ciência e Tecnologia do Estado de Pernambuco (FACEPE) pela concessão de bolsa de doutorado que permitiu a realização do presente artigo.
Em meio ao esforço atual para se repensar o corpo - tradicionalmente concebido com base na perspectiva dicotômica que tanto o trata como uma coisa extensa a partir da concepção cartesiana quanto o exalta nas suas virtudes de vontade de poder a partir de Nietzsche -, neste ensaio, pretendemos considerá-lo em uma perspectiva fenomenológico-existencial. Heidegger (2001) aponta a carência de reflexão mais aprofundada sobre o tema a partir da sua ontologia fundamental, que aborda os fundamentos do ser e da existência humana. Aqui propomos uma reflexão que expõe alguns aspectos da corporeidade veiculados por Merleau-Ponty 
Critelli (1996), retomando a trajetória do pensamento ocidental, identifica que o pressuposto de que existe coincidência entre ser e substância e verdade e representação remonta a Platão e a Aristóteles.
(1999), articulando o corpo com a relação entre ser e tempo e com a relação entre ser e ente - ambas presentes na perspectiva fenomenológico-existencial.

A importância de refletir a respeito do corpo na atualidade reside no fato de que o modo como ele foi concebido tradicionalmente já não é suficiente para expressar as vivências atuais do homem com sua corporeidade. Procuramos, então, mostrar como essa insuficiência no modo de vermos o corpo se vincula à crise - apontada por Heidegger (2006) - pela qual a sociedade contemporânea passa por viver de acordo com um modo técnico, cientificizado e, acrescentaríamos, capitalista. Esse modo de pensar e de ser predominantemente técnico, segundo o pensamento heideggeriano, teria levado o homem a perder de vista o ser aí no mundo. Embora reconheça que, no fundo, o Ocidente nunca deixou de questionar sobre o ser, o filósofo considera que o tenha feito de modo a atribuir ao ser uma ideia conceitual, permanente, imutável e universal. O filósofo propõe, então, uma ontologia fundamental, ou seja, uma ontologia que busca os fundamentos, as condições pelas quais o ser acontece: como impermanente, mutável, existente a partir de um sentido constituído na existência, e não na sua constância.

O artigo está dividido em quatro seções. Na primeira, expomos a trajetória histórica de nossas concepções de corpo com base na tradição; na segunda, mostramos a relação existente entre ser e tempo no pensamento heideggeriano e como o corpo se vincula a essa relação; na terceira seção, apresentamos alguns aspectos do corpo segundo o pensamento fenomenológico de Merleau-Ponty, e, na quarta, articulamos as concepções de Merleau-Ponty e de Heidegger sobre o corpo.

\section{O corpo em uma perspectiva dicotômica}

A perspectiva que domina o pensamento ocidental desde Platão se caracteriza pela busca da permanência das coisas, por isso privilegia, quase exclusivamente, o traço teórico e abstrato do pensamento como fonte de verdade. O corpo, concebido como pura matéria, é apenas mera aparência e transitório, portanto, desprezível. Ele se contrapõe à razão - nossa dimensão valorizada pela filosofia ocidental pósplatônica. Mesmo na Idade Média, quando o modo de pensar do homem ocidental se confundia com os dogmas religiosos cristãos, dominava a concepção dualística: um criador, Deus, e as criaturas, as coisas e nós mesmos. O corpo, em tal contexto, estava em oposição à alma e continuava sendo visto como algo passageiro, transitório, ao qual não devíamos ter apego. O pensamento devia voltar-se para as coisas perenes, e não para a finitude e a limitação do corpo.

Critelli (1996), retomando a trajetória do pensamento ocidental, identifica que o pressuposto de que existe coincidência entre ser e substância e verdade e representação remonta a Platão e a Aristóteles. De acordo com Platão (1999), havia um mundo ideal e não aparente de que só o espírito poderia recordar-se (processo chamado de reminiscência), pois já teria estado lá antes de vir ao mundo sensível (transmutação). $\mathrm{O}$ ser, para Platão, é imaterial e não sensível; o ente, material e sensível (o próprio corpo é também um ente sensível). Já conforme Aristóteles (1969), o inaparente do ser, seu conceito, não está em um mundo à parte do mundo aparente, sensível, mas no mundo sensível mesmo, e o acesso a este pode ser realizado pelo intelecto. Aristóteles consolidou, assim, o primeiro método lógico de fazer conhecimento, ou seja, as ideias seriam produzidas pelo pensamento ao 
seguirem seus procedimentos lógicos. A partir daí, consolidou-se a ideia de coisa em si e de consciência em si, duas instâncias que existem e se sustentam separadamente.

Descartes (2008), por sua vez, reafirmou a separação de coisa em si e de consciência em si na noção de sujeito e objeto. Sobre tal noção se apoiaram as ciências naturais. Observação, mensuração, classificação e verificabilidade tornaram-se os procedimentos de investigação que permitiram a certificação de algo segundo o modelo metodológico técnico proposto por esse autor.

Nesse modelo, só se tem certeza de algo se esse algo tiver patência e tangibilidade. O corpo consolidou-se como mero acessório, e é considerado coisa, extensão, em oposição a subjetividade, a racionalidade, a possibilidade de pensar (res extensa, objeto, e res cogitans, sujeito, segundo Descartes).

Não apenas a anatomia, a fisiologia e a Medicina se desenvolveram nesse contexto do pensamento ocidental, mas também a Revolução Industrial e o capitalismo só foram possíveis a partir da mensurabilidade e do domínio que norteiam o pensamento técnico. Com estes, surgiram o homemconsumidor e a mercadoria consumida. Entre um e outro “(...) se instaura, de modo feroz, um vínculo de desgaste, de corrosão, de esgotamento, de aniquilamento, de destruição - significados esses presentes no vocábulo latino consumere" (Michelazzo, 2003, p.111). O homem perdeu, assim, o sentido, a proximidade e a intimidade com as coisas, com os lugares e com as pessoas. O corpo-objeto e o corpo-mercadoria assumiram valorizações mórbidas.

Atualmente, nossa sociedade capitalista promove uma relação com o corpo na qual o utilizamos como coisa para mostrar ao mundo quem gostaríamos de ser. Essa relação indica uma dicotomia entre nós e nosso corpo, entre ser e aparência. Tal dicotomia não é mera constatação teórica; ela mostra a nossa relação fragmentada com o mundo, da qual nossa intimidade com o mundo e a nossa espontaneidade de ser se perderam. Assim, não vivemos uma relação de autenticidade que nos mostra como somos; na verdade, temos uma aparência - evidente na nossa presença corporal, por isso tão explorada -, mas somos outra coisa. A incoerência entre o que sou e o que mostro que sou denuncia o laço de desunião íntima com o mundo. Essa incoerência pode ser vivida de diversas formas, por exemplo, dissimulando com a intenção de enganar e obter vantagem sobre o outro, de modo individualizante, ou ao sofrer por nos sentirmos não pertencentes e estranhos ao mundo.

Ademais, embora nos tempos atuais o corpo seja concebido como o nosso cartão de visitas e tratado de forma a evitarmos a ação do tempo da impermanência e da finitude por meio de cirurgias estéticas e de outras formas de cuidado com a aparência, nossa vivência corporal se dá nas dimensões temporal, impermanente e finita.

De qualquer maneira, não podemos negligenciar nosso corpo, ou sua vingança será nos tornar anoréxicos, bulímicos, obesos, denunciando desesperadamente um lugar que não quer para si. Assustados, respondemos com uma supervalorização. Entretanto, parece que o corpo quer nos dizer que as dicotomias nas quais temos vivido, além de torturantes, não respondem ao seu lugar. Mas qual seria o lugar do corpo? O que mostram essas dicotomias? O que elas escondem? Poderíamos descobrir algo que nos apontasse outro modo de ser menos cindido retomando a construção histórica dessas dicotomias?

Dentro de tal realidade é que situaremos a corporeidade na seção seguinte. 


\section{Situando o corpo nas noções de ser e de tempo propostas por Heidegger}

A questão do corpo apresentada na seção anterior vincula-se a um modo de compreender o ser humano. Para repensar o corpo, optamos por refletir a respeito da condição humana de existir à luz da compreensão de ser e de tempo desenvolvida por Heidegger.

Conforme postula Heidegger (2001, 2006, 2008), o pensamento ocidental se esqueceu do sentido do ser, que é dinâmico, pois sempre perguntou pelo ser baseandose no imutável, constante e permanente dentro da frequente mutabilidade do mundo (movimento do tempo). A ontologia (estudo do ser) proposta por Heidegger é fundamental, porque considera o ser a partir de seu fundamento, ou seja, existindo na sua impermanência e mutabilidade consideradas fundamentos da existência.

No entendimento do mesmo autor, o tempo é a dimensão existencial do que passa, do que se move, do que nunca permanece o mesmo, por isso os conceitos, que anulam a qualidade de impermanência do real, são atemporais. Heidegger $(2001,2008)$ critica a hegemonia que o pensamento metafísico pode atingir, porque apenas se considera verdadeiro o permanente, o constante, e, portanto, o que é passível de mensuração e cálculo. Inegavelmente, a perspectiva técnico-científica é extremamente válida e útil na produção de conhecimento e de tecnologia; no entanto, se a sociedade pensar e viver exclusivamente a partir dela, as pessoas correm o risco de restringirem sua vivência, sua abertura afetiva e sua disponibilidade para o outro a um modo previsível e controlado, próprio dessa perspectiva.
O ser concebido como presença constante diz respeito apenas a uma de suas dimensões: a do verbo ser, no presente, é, algo subsistente, simplesmente dado, observável, calculável e passível de teorização. Essa dimensão do ser não é, de forma alguma, equivocada, mas parcial e somente possível por meio de elaboração intelectual a partir do sentido fundamental e originário do tempo. Por esse motivo, Heidegger (2008) busca a compreensão do tempo apoiando-se no sentido originário, que diz respeito à origem do tempo - refere-se ao questionamento: - como é o tempo?, a partir do qual outras concepções foram geradas, por exemplo, a que se tornou a corrente, quase hegemônica, como sucessão quantitativamente mensurável de agoras (tempo do relógio e do calendário).

O tempo não é, para Heidegger (2008), um conceito concebido fora do homem. Embora nunca cheguemos a saber o que é o tempo, justamente por termos com ele relação tão estreita, Heidegger identifica profunda vinculação entre tempo e existência, daí o título de uma de suas principais obras: Ser e Tempo. Sobre esses dois aspectos, afirma Michelazzo: "Um é condição do outro, um não é sem o outro" (2003, p.115). Perguntando não o que é o tempo (o que levaria a uma definição que é conceitual e estática), mas como é o tempo, a partir de nossa experiência, damo-nos conta de que o tempo passa. Se falamos de nossa experiência, então, quem passa: nós ou o tempo? Ambos passam. Aí está a conexão entre ser e existência.

Nessa perspectiva, compreende-se a existência como meu passar. Segundo Michelazzo (2003), Heidegger, buscando conexão mais íntima entre existência e tempo, afirmou, ao final de uma conferência, em 1924, que "tempo é existência", e que "a existência é o tempo". Os dois seriam, na realidade, um. "Esse passar da existência e do tempo, entretanto, se dá de três modos: é um passar 
que aguarda (futuro), um passar que fica junto (presente) e é um passar que conserva (passado)" (Michelazzo, 2003, p.116).

Conforme Heidegger (2008), a essência do ser-aí está na sua existência. Nessa concepção, o filósofo reuniu duas instâncias que, desde Platão e Aristóteles, vinham sendo consideradas separadamente pelo pensamento ocidental. A existência refere-se a como algo se mostra; já a essência (o que algo realmente é) está oculta, refere-se a um âmbito suprassensível ou racional, além e diferente do que se mostra, e somente pode ser acessada pela razão (Aristóteles) ou pela reminiscência (Platão).

A coincidência entre essência e existência aponta a coincidência entre o que é e o que se mostra. Se o que é é o que se mostra, então não há como engessar a existência em um conceito, e ela passa a ser compreendida como possibilidades de ser. Heidegger (2001) chama de ontológico o horizonte em que alguma coisa se pode mostrar. A algo que se mostra em suas condições de possibilidade, Heidegger chama ôntico. Por isso, segundo o mesmo autor, tradicionalmente se considera a existência na sua perspectiva ôntica (substancialista). De outra parte, ao compreendê-la na perspectiva ontológica, ele irá utilizar o termo alemão Dasein, que significa ser-aí (Das, aí/ abertura, e sein, ser). Da palavra existentia, do latim, deriva existência (em português, tem sentido semelhante, significa sustentar para fora) (Michelazzo, 2003, p.117). Ex quer dizer para fora de si mesmo, e sistere, sustentar.

A relação entre corpo e existência pertence à mesma ordem da relação entre existência e tempo: ambos estão profundamente envolvidos um com o outro, um não acontece sem o outro. A existência acontece pelo corpo, corporalmente. Há também relação estreita entre corpo e tempo. Assim, em princípio, a finitude imposta pela morte ao corpo confere a este a primeira dimensão temporal. Pelo fato de sabermos que teremos um fim, ocupamo-nos com as pessoas e com as coisas. Se a vida fosse eterna, seria uma vida de adiamento.

Durante a vida, o corpo vai existindo, passando com o tempo. Quando nascemos, nossa mobilidade é extremamente limitada, e nossa existência/corpo depende do cuidado do outro em todos os sentidos. Quando aprendemos a andar, ganhamos liberdade, passamos a conquistar um mundo. $\mathrm{Na}$ adolescência, o corpo vive as metamorfoses da infância para a idade adulta. Vivenciamos isso acompanhando a mudança no tom de voz, o surgimento dos pelos pubianos, o crescimento dos órgãos genitais e o aumento da estatura e da massa muscular, que nos possibilita realizar novas tarefas. $\mathrm{Na}$ idade adulta, somos um corpo que trabalha, que procura o sustento da família e as realizações pessoais. Na velhice, ele vai perdendo a autonomia no mundo e volta a necessitar de cuidado - fase em que nos voltamos mais para nós mesmos e, aos poucos, nos desligamos do mundo. Corporalmente, nossas possibilidades no mundo vão restringindo-se.

O passado e o futuro presentificam-se no corpo. Quando determinado acontecimento do passado me atormenta e sofro por ele, meu corpo se agita, esquenta, a visão turva, a cabeça dói, no presente. Se me preocupo demais com um compromisso futuro, meu corpo não dorme, a preocupação é vivida corporalmente. $\mathrm{O}$ aspecto biológico do corpo não tem autonomia para dormir sozinho enquanto estou preocupado.

\section{Contribuições de Merleau- Ponty para a compreensão dos fenômenos corporais}

Em francês, empregam-se dois termos para carne: viande significa carne morta, 
como a carne de animal em um açougue; chair quer dizer carne viva em corpo vivo. Merleau-Ponty (2007) considera que a chair é o meio em que homem e mundo estão entrelaçados. O homem-chair está sempre entrelaçando o mundo. O homem não é o centro do mundo. Ele constitui o mundo como o mundo o constitui. O homem é um ser no mundo, em um processo de mútua constituição com o mundo. A reflexão faz ver, inclusive, que existe certa aproximação entre Merleau-Ponty e Heidegger, pois o filósofo alemão também postula que não há separação entre homem e mundo e que ambos se constituem mutuamente. A chair e seus movimentos de existência evidenciariam o entrelaçamento do homem com o mundo em sua cooriginalidade e coconstituição.

Aqui nos limitaremos a mostrar como Merleau-Ponty compreende o corpo sob o ponto de vista de três aspectos fundamentais: o espaço e a motricidade, a sexualidade e a linguagem. Pretendemos compreender alguns desdobramentos possíveis do corpo, tendo como ponto de partida uma reflexão sobre o corpo apenas acenada na obra de Heidegger.

\section{Espacialidade e motricidade}

Ao contrário do que nos ensinam as ciências naturais, o espaço objetivo - um espaço neutro onde as coisas se relacionam umas com as outras de acordo com suas posições - não é o fundamento espacial ou o fundo de espaço no qual vivemos nossa espacialidade. Merleau-Ponty (1999) mostra o contrário: nossa vivência espacial como corpos situados no mundo em relação às coisas e aos outros é que nos permite a construção racional posterior de um espaço objetivo, o qual, conforme procuramos mostrar nesta seção, é formado pelas referências de nosso corpo situado no mundo. Da mesma forma, não nos movemos no mundo de acordo com nossas representações objetivas de espaço, mas segundo nossa intencionalidade que nos situa no mundo. Isso acontece por meio de nossas possibilidades corporais, sem intermédio da razão. Assim, não pensamos para realizar um gesto motor; simplesmente agimos.

A espacialidade do meu corpo não é a mesma dos objetos exteriores. Ele se coloca de determinado modo, visando a executar determinada tarefa. Por isso, a espacialidade do corpo é de situação, ou seja, diz respeito a como me situo no mundo em relação aos outros objetos e às outras pessoas. Os objetos exteriores estão dispostos no espaço, de modo que cada um tem uma posição em relação ao outro, ou uma espacialidade de posição. Eles se posicionam para alguém que vê e/ou estabelece essa disposição. Assim, podemos dizer que um objeto está atrás ou ao lado de outro, por exemplo.

Conforme a concepção cartesiana, poderíamos entender que precisamos do espaço objetivo para conseguir orientação espacial; no entanto, ocorre o contrário. Por exemplo, se digo que meu livro está sobre a mesa, situo-me na mesa ou no livro em pensamento e estabeleço com eles uma relação, ou seja, originalmente, o meu corpo mantém relação com os objetos exteriores que o circundam. Portanto, a própria orientação do espaço objetivo me faz dizer ao lado de e em cima de. Isso não é abstração pura que me exclui como sujeito de uma realidade objetiva neutra, mas, ao contrário, funda-se no meu modo de me situar como corpo em relação aos objetos ao meu redor e a como intenciono determinado objeto, mesmo abstratamente. É meu corpo que, no mundo, no espaço orientado por ele no mundo, me dá a dimensão de em cima, em baixo, sobre ou sob.

Só há espaço porque há corpo. A espacialidade do corpo, por sua vez, só se realiza na ação. Eis aí a relação íntima entre espacialidade 
e motricidade. O espaço não está acessível em forma de representação em dimensão intelectível, separada do meu corpo. Por tal razão, o sujeito

(...) posto diante de uma tesoura, sua agulha e suas tarefas familiares não precisa procurar suas mãos ou seus dedos porque eles não são objetos a se encontrar no espaço objetivo, ossos, músculos, nervos, mas potências já mobilizadas pela percepção da tesoura ou da agulha, o termo central dos 'fios intencionais' que o ligam aos objetos dados (Merleau-Ponty, 1999, p.153)

O corpo não apenas está situado no concreto, no âmbito das tarefas práticas, mas também está aberto às situações verbais e fictícias. O corpo se mobiliza no real e no virtual. Assim, quando nos entristecemos, recolhemonos, fechamo-nos para o mundo concreto, fechamos nossas pálpebras e lacrimejamos, o corpo se põe triste. Da mesma forma, quando refletimos sobre algo ou desejamos algo não presente na forma de objeto tangível pelo volume e grandeza, desviamos o olhar do nosso redor para nosso mundo desejado. Nesse momento, o corpo pode até sorrir, mas sorri para o mundo sonhado.

Não há também separação entre o gesto e a percepção do gesto. Quando faço um gesto para alguém, essa pessoa imediatamente o compreende e responde a ele. É o que Merleau-Ponty mostra com o seguinte exemplo:

O fundo do movimento concreto é o mundo dado, o fundo do movimento abstrato, ao contrário, é construído. Quando faço sinal para um amigo se aproximar, minha intenção não é um pensamento que eu prepararia em mim mesmo, e não percebo o sinal em meu corpo. Faço sinal através do mundo, faço sinal ali onde se encontra meu amigo; a distância que me separa dele, seu consentimento ou sua recusa se lêem imediatamente em meu gesto, não há uma percepção seguida de um movimento, a percepção e o movimento formam um sistema que se modifica como um todo (1999, p. 159-160)
Quando entramos em nossa casa, sabemos a disposição dos cômodos. Sabemos que entrar pela sala significa igualmente caminhar ao lado da varanda. Tal saber adquirido, no entendimento de Merleau-Ponty, não está alojado na consciência sob forma de categoria; estamos falando, sim, de nossa capacidade de representar. Mas representar não quer dizer aqui formar conceitos, deixá-los guardados em um compartimento imaterial e acessá-los no momento em que deles necessitarmos; "representar é situar-se por um momento em uma situação imaginária e dividir-se em mudar de meio" (MerleauPonty, 1999, p. 189). Se pensamos em nossa casa, por exemplo, nossa intencionalidade dirigida a ela naquele momento é que nos dá a disposição dos cômodos. A motricidade, portanto, é a intencionalidade original, porque é a partir da intencionalidade de nosso corpo dirigida a objetos que temos condições de representar um mundo. Antes de eu penso, somos eu posso. Representar, então, para Merleau-Ponty, diz respeito a dar conta de como estou situado em relação a determinados objetos ou de como me intenciono em direção a eles.

No gesto de pegar certo objeto, minha mão não se dirige a um objeto representado, mas ao que existe para ela e para o qual se projeta, se dirige. Por isso Merleau-Ponty questiona o fato de comumente entendermos que a cabeça envia uma ordem motora à mão. É a mão mesma, claro, integrada à totalidade do corpo, que se dirige ao objeto que quero pegar. Isso não impede de o gesto ter uma correspondência em sinapses cerebrais, mas está longe de se provar que o cérebro determinou aquela ação motora. Essa crença, levada ao extremo, nos faria concluir que nossa motricidade é determinada biologicamente, e que não podemos ter um gesto voluntário.

O movimento não resulta de um instante anterior, mas vincula-se aos instantes 
anteriores no sentido de que estes estão envolvidos no presente, assim como o momento presente também envolve os instantes que completarão o movimento. No plano da motricidade, tal relação do corpo com o tempo se aproxima da condição temporal do dasein, que, para Heidegger, presentifica o passado e o presente no momento atual. Assim, se tenho um sentimento ligado à memória de determinado evento passado, o sentimento não resulta do evento, mas expressa como torno presente esse evento hoje. O futuro também está no presente como perspectiva de vir a ser: nossa destinação, para onde nos dirigimos e como nos dirigimos a esse ainda não sido.

Diferenciando-se de concepções sobre o corpo fundamentadas na dicotomia da realidade, as quais separam o corpo de uma instância suprassensível, Merleau-Ponty afirma que o corpo habita o espaço e o tempo. Ele não está no espaço e no tempo, porque estar indica uma posição em tempo e espaço objetiváveis - espaço mensurável em metros, classificado como urbano ou rural ou delimitador de cidades e países, e tempo mensurável no relógio, que se marca no calendário. Já habitar implica relação de familiaridade com o mundo. O mundo é habitado pelo ser humano, cujos gestos e ações, nesse sentido, são hábitos.

Quando dirigimos um carro, não precisamos calcular nem medir o espaço para sabermos se vamos passar ou não. Não é a medição do coeficiente de atrito do asfalto que nos fará reduzir a velocidade ao sentirmos a pista mais lisa. O carro, portanto, se torna a extensão do nosso corpo no mundo. Ampliamos, por meio de um instrumento como o carro, nossas possibilidades quanto a volume e grandeza. Dessa forma, o hábito de dirigir me torna um corpo ampliado por uma estrutura metálica que se move velozmente no espaço. O corpo se une ao carro e ganha a velocidade deste, tendo-a ao seu alcance.
No exemplo a seguir, pensaremos somente sobre a relação do cego com a bengala quanto à orientação espacial. Isso não significa restringir tal função ao uso da bengala, pois consideramos que outros sentidos do cego, como a audição, mais aguçados que em pessoa não cega, são também fundamentais. A verdade é que ele se habitua à bengala de maneira semelhante à maneira como nos estendemos a um carro quando dirigimos, mas sua bengala tem função permanente. O carro se estende ao nosso corpo somente quando queremos ir rapidamente a lugares; ele não é nosso andar; a visão dá a distância espacial entre as coisas. Desprovido dessa possibilidade de distanciar as coisas, o cego tem a bengala como o seu olhar, o que se torna muito familiar e íntimo para ele e que se circunscreve nas possibilidades dadas pela bengala. Assim, a bengala passa a ser a medida desse olhar do cego. O carro e a bengala, portanto, não são mais meros objetos para quem os utiliza; são instrumentos, eles se tornaram "(...) potências volumosas, a exigência de um espaço livre" (Merleau-Ponty, 1999, p.198).

Entretanto, convém ampliar nosso entendimento sobre compreensão, a fim de situar o que estamos caracterizando como hábito. A compreensão é o encontro de como nos dirigimos a algo e nos situamos no mundo com o que é dado. Compreender significa nos situarmos em tal encontro. É nesse sentido que Merleau-Ponty afirma que o corpo compreende na aquisição do hábito.

Segundo Merleau-Ponty, o corpo é (...) a origem de todos os outros (espaços expressivos), o próprio movimento de expressão, aquilo que projeta as significações no exterior dando-lhes um lugar, aquilo que faz com que elas comecem a existir como coisas, sob nossas mãos, sob nossos olhos. (1999, p. 202)

Mais adiante, na seção sobre linguagem, veremos que a expressão verbal constitui 
uma modalidade de expressão originada pelo corpo, ou mesmo corporal.

\section{Corpo como ser sexuado}

A sexualidade diz respeito à dimensão do nosso meio afetivo. O modo de desejarmos e de amarmos um objeto é inseparável do modo como o objeto existe para nós. Em outras palavras, o modo como um objeto tem existência para nós é profundamente marcado por como o desejamos e o amamos. De acordo com Heidegger (2008), a disponibilidade afetiva nos abre para o mundo, para os outros e para os entes e, a partir dela, eles teriam existência para nós. $\mathrm{O}$ modo como nos abrimos afetivamente para o mundo nos permite que nós sejamos de determinado modo e que o mundo também exista para nós de determinada maneira.

Nesse sentido, a reflexão de Merleau-Ponty (1999) sobre a sexualidade se aproxima da condição existencial de disponibilidade afetiva do pensamento heideggeriano. Mesmo a concepção de sexualidade para Freud se aproxima da compreensão fenomenológica, no sentido de ambas não considerarem a sexualidade como aspecto genital, biologicamente determinado. A libido, segundo Freud, não está ligada ao instinto; ela é energia da pulsão de vida, ligase ao erotismo, e não à reprodução. MerleauPonty reconhece haver profunda relação entre sexualidade e existência, afirmando que existe osmose entre elas. No entanto, tal relação não é do tipo causal, em que uma determina a outra, e sim, a que aponta o fato de a existência sempre acontecer a partir de um modo sexual, afetivo, de nos colocarmos no mundo e de nos abrirmos para ele. Por isso, para o filósofo, é impossível dizer se um gesto é sexual ou não sexual.

A posição de Merleau-Ponty em relação à sexualidade diferencia-se da de Freud, pois, segundo aquele filósofo, o psicanalista, ao observar a profunda relação entre existência e sexualidade, tentou explicar a primeira pela segunda. No entanto, para MerleauPonty, nem existência, nem sexualidade se determinam, porque estão diluídas uma na outra, de maneira que a existência nos é dada a partir de como estamos situados sexualmente no mundo. O filósofo utiliza um exemplo que esclarece a diferença entre ambos ao considerar a sexualidade: o caso de uma jovem que se tornara afônica depois de a mãe ter-lhe proibido de falar com o rapaz de quem gostava. Conforme MerleauPonty (1999, p. 222), uma “(...) interpretação estritamente freudiana colocaria em questão a fase oral do desenvolvimento da sexualidade". Entretanto, de acordo com o filósofo, não foi apenas a existência sexual que se "fixou na boca", mas também a emoção da jovem expressa na forma de afonia, porque a fala constitui a função corporal mais ligada à existência com o outro, à coexistência. Portanto, a mãe da jovem lhe proibiu não só uma possibilidade afetivo-sexual mas também, em razão da importância do rapaz naquele momento, a possibilidade de ser para o outro, que certamente envolve a sexualidade.

Nossa sexualidade não está ligada a como representamos mentalmente estímulos sexuais externos. A eroticidade, por exemplo, não acontece a partir de representação mental que fazemos do objeto de desejo nem se determina por uma estimulação biológica; ela acontece a partir da possibilidade de nos colocarmos em situação erótica em relação ao corpo de outrem. É o que afirma MerleauPonty no seguinte trecho:

A percepção erótica não é uma Cogitatio que visa a um Cogitatum; através de um corpo, ela visa a um outro corpo, ela se faz no mundo, e não em uma consciência. Um espetáculo tem para mim uma significação sexual não quando me represento, mesmo confusamente, sua relação possível aos órgãos sexuais ou aos estados de prazer, mas 
quando ele existe para meu corpo, para essa potência sempre prestes a armar os estímulos dados em uma situação erótica, e a ajustar a ela uma conduta sexual. Há uma 'compreensão' erótica que não é da ordem do entendimento, já que o entendimento compreende percebendo uma experiência sob uma idéia, enquanto o desejo compreende cegamente, ligando um corpo a um corpo (1999, p. 217)

A sexualidade tem intencionalidade que segue o mesmo movimento da existência; logo, não é função corporal que reage automaticamente a estímulos externos ou internos, dissociados de como o ser está situado no mundo por meio de seu corpo, nem é um ciclo autômato (MerleauPonty, 1999, p. 218), conforme se pode compreender em uma posição determinista.

Um fundamento da sexualidade reside no fato de meu corpo ser, ao mesmo tempo, objeto para o outro e sujeito para mim. Isso não quer dizer que só podemos vivenciar o corpo a partir da dicotomia radical sujeitoobjeto, cuja limitação apontamos desde o início deste ensaio. Não se conclua, entretanto, que o corpo do outro seja equiparado a qualquer objeto mundano; trata-se, sim, de objeto especial. Em outras palavras, vejo o corpo do outro nas suas possibilidades corpóreas humanas, capaz de abraçar, de realizar tarefas, de amar.

Merleau-Ponty não entende a afonia como recusa de falar ou a anorexia como recusa de viver, e sim, uma recusa ao outro e ao futuro que se torna situação de fato pelo corpo. "O papel do corpo é assegurar essa metamorfose. Ele transforma as idéias em coisas, minha mímica do sono em sono efetivo. Se o corpo pode simbolizar a existência, é porque a realiza e porque é sua atualidade" (MerleauPonty, 1999, p. 227). Consideramos tal afirmação de Merleau-Ponty decorrência direta da afirmativa de Heidegger de que o ser se manifesta pelo ente-homem. O corpo (ente-homem) realiza e atualiza a existência, ou seja, deixa-se manifestar pelo ser, coorigina-se e coexiste com o mundo.

A sexualidade tem importância diferencial dentre as condições de nossa existência, porque nela engajamos a vida pessoal. Fazemos isso porque

(...) nosso corpo é para nós o espelho do nosso ser, (...), uma corrente de existência dada, de forma que nunca sabemos se as forças que nos dirigem são as suas ou as nossas - ou antes, elas nunca são inteiramente suas nem nossas (MerleauPonty, 1999, p. 236), por isso a sexualidade nunca é ultrapassada nem fechada em si mesma.

\section{A linguagem compreendida como gesto}

A dicotomia sujeito-objeto proposta pelo modelo cartesiano deu origem a duas correntes de pensamento: o intelectualismo, que privilegia o subjetivismo, e o empirismo (ou mecanicismo), que privilegia o objetivismo. No âmbito da concepção da linguagem, ambas as correntes consideram separáveis pensamento e fala - ou um é causa do outro, ou um representa o que outro expressa. Para Merleau-Ponty (1999), a fala e o pensamento constituem dois momentos de um mesmo gesto, que só se realiza por meio do corpo, por isso o autor afirma: “(...) Para poder exprimi-lo, em última análise, o corpo precisa tornar-se o pensamento ou a intenção que ele nos significa. É ele que mostra, é ele que fala" (Merleau-Ponty, 1999, p. 267).

A linguagem, fenômeno do corpo, é uma modalidade de gesto. Como todo gesto, a fala só acontece segundo as possibilidades expressivas do corpo, como vociferar e soltar ar silibante, e, ao mesmo tempo, ela constitui um mundo de significados que expressam intenções e disposição emocional. 
Tal mundo de significações se refere a uma rede significativa intersubjetiva já adquirida, permitindo que a fala seja compreendida pelo outro. No entanto, ela não se relaciona à rede intersubjetiva como processo causal, nem se relaciona, por acesso intelectual, a representações mentais preexistentes. A fala do outro habita meu corpo; há reciprocidade entre minhas intenções e desejos e a fala do outro e vice-versa. Só por isso há fala. A rede intersubjetiva é apenas o meio (linguístico) possibilitador da fala. E ela ainda não pressupõe o pensamento. Falar não é unir-se ao objeto por meio de representação idealista (como o idealismo concebe representação), nem por uma intenção de conhecimento. A denominação dos objetos é seu próprio reconhecimento, e não, anterior a ele.

(...) A fala não é o signo do pensamento, se entendemos por isso um fenômeno que anuncia outro, como a fumaça anuncia o fogo. A fala e o pensamento só admitiriam essa relação exterior se um e outro fossem tematicamente dados; na realidade, eles estão envolvidos um no outro, o sentido está enraizado na fala, e a fala é a essência exterior do sentido (Merleau-Ponty, 1999, p. 247)

Compreendemos além do que pensamos espontaneamente. Isso mostra que o pensamento não se relaciona com a fala com base em processo associativo, conforme sustenta o intelectualismo. Há um pensamento que fala (tanto no escutar e ler quanto no falar e escrever), e isso é desconsiderado pelo intelectualismo.

Pronunciar uma palavra é o único modo de representá-la. Assim como outras modalidades da consciência corporal, a imagem verbal constitui uma das modalidades de gesticulação fonética. Fala e pensamento, portanto, estão arraigados um no outro, não são dados separadamente. A fala é a essência exterior do sentido, que, por sua vez, está fundado na fala.

A duplicação e a vociferação que revestem o pensamento trazem e contêm em si o seu sentido. A fala tem a própria potência de significação. A operação expressiva realiza a significação da fala, não a traduz. Ela, como (todo) gesto, contém seu sentido, o que permite a comunicação, que acontece de mim para um outro "sujeito falante", que tem determinado modo de ser e com "um mundo que ele visa" (Merleau-Ponty, 1999, p. 249). Não nos comunicamos com pensamentos nem com representações, conforme proposta do intelectualismo.

A fala é um gesto cuja origem é o "silêncio primordial" (Merleau-Ponty, 1999, p. 250), e que, ao mesmo tempo, rompe esse silêncio. A sua significação é um mundo, daí a comunicação acontecer não pela apreensão de determinado sentido, mas pela compreensão do gesto do outro. Tal compreensão só é possível porque existe reciprocidade entre minhas intenções e os gestos dos outros. Dessa forma, minhas intenções podem habitar o corpo do outro, assim como as intenções do outro podem habitar meu corpo.

Tanto a compreensão do outro quanto a percepção das coisas se dão por meio do corpo. O sentido do gesto, portanto, está na sua expressão (jamais dado separada ou anteriormente a ele em uma representação), e estrutura um mundo de significações. Quanto à gesticulação verbal, ela se serve de significações já disponíveis, estabelecidas por expressões anteriores, comuns aos falantes. $\mathrm{O}$ sentido da fala é o modo como esta articula as significações adquiridas.

A fala constitui uma das possibilidades da potência irracional humana, que cria significações e as comunica. Sua singularidade entre as operações expressivas reside na possibilidade de criar um saber intersubjetivo a partir de sua sedimentação. Por isso, só a metalinguagem, ou falar sobre a fala, é possível, o que não ocorre em outras 
modalidades expressivas, como pintar sobre a pintura e cantar sobre a música. A atividade categorial, ou nossa possibilidade de estabelecer categorias, é apenas um modo de nos relacionarmos com ou de estarmos no mundo, ou mesmo um modo de configurarmos nossa experiência. O pensamento cartesiano e as ciências que nele se fundamentam elegem tal possibilidade como a mais verdadeira ou confiável, e invalidam as outras.

A partir do momento que o homem faz uso da linguagem para estabelecer uma relação viva consigo mesmo ou com seus semelhantes, a linguagem não é mais um instrumento, não é mais um meio, ela é uma manifestação, uma revelação do ser íntimo e do elo psíquico que nos une ao mundo e aos nossos semelhantes (Merleau-Ponty, 1999, p. 266)

Tal modo de viver a linguagem, proposto por Merleau-Ponty, nos sugere um modo de viver com os outros (e de construir um mundo) mais humano. Compreendendo e procurando estabelecer essa possibilidade de linguagem, podemos nos tornar menos fragmentados e menos determinados pelos ditames de uma época em que a impessoalidade e o individualismo imperam.

\section{Algumas aproximações entre Merleau-Ponty e Heidegger}

Considerando o entendimento de MerleauPonty - que fundamenta sua reflexão sobre a corporeidade na noção de entrelaçamento entre homem e mundo (homem-chair), em que o homem não é o centro do mundo, mas um ser no mundo, em processo de mútua constituição com o mundo como podemos situar o corpo na relação entre ser e ente proposta por Heidegger? Imediatamente nos ocorre que o corpo tem vinculação profunda com a dimensão de ente do homem. Podemos considerá-lo, pois, a dimensão entitativa do homem? $\mathrm{O}$ primeiro passo, então, é refletir sobre que tipo de ente é o ente-corpo. Nesse âmbito, convém esclarecer, a dimensão entitativa do corpo não devia ser compreendida como a das ciências naturais, que, de costume, concebem o ente como coisa ou como coisa extensa, com realidade exterior à consciência e com existência independente da qual o sujeito se assegura em razão de sua constância. Entendemos o ente, aqui, profundamente relacionado com o ser.

Tendo a questão do ser como tema central de seu pensamento, Heidegger (2001, 2008) propôs uma filosofia que rompesse as representações metafísicas sustentadas pelas qualidades que pudessem ser mensuráveis, quantificáveis e calculáveis. Tal filosofia compreende e fala do homem a partir de suas condições existenciais. O homem é compreendido como dasein (ser-nomundo ou ser-aí). Homem e mundo são coconstitutivos e cooriginários, não são duas realidades existentes separadamente - a de sujeito e a de objeto.

Assim, para Heidegger (2001, 2008), não existe um aparelho psíquico ou mecanismo causal externo que determina o comportamento humano: só na dimensão de ser-no-mundocom-os-outros se entende o ser humano. A propósito disso, a filosofia heideggeriana busca as suas condições ontológicas, cuja angústia é a condição originária.

Conforme Heidegger, a vida não dá ao homem o mesmo acolhimento que oferece aos entes, pois estes últimos têm lugar determinado no mundo como destinação de sua vigência: uma pedra se destina a ser pedra, uma flor, a ser flor, e um animal, a ser animal. $\mathrm{O}$ homem tem no mundo a experiência originária de inospitalidade, pois o mundo não lhe dá destino, nem ele mesmo pode antecipar seu vir a ser. Assim, diante da angústia e da liberdade, ele constrói o mundo humano com os outros. 
O mundo é a trama de significados humanos que vão sendo tecidos nas relações dos homens entre si e destes com as coisas. Logo, não há uma essência de algo, mas múltiplas possibilidades de algo se mostrar e de ser vivido por nós. O que alguma coisa é, no entendimento de Heidegger (2001, 2008), diz respeito a determinados aspectos da coisa para os quais o homem se abre e com os quais entra em contato. No construir do mundo, o homem se constrói mutuamente.

Diferenciado da concepção metafísica como objeto, o que é objetivável (passível de observação, mensuração e cálculo) -, o ente, segundo Heidegger, é aquilo que tem sustentação na rede de significados e sentidos tecida pelos seres humanos; ele é iluminado pelo ser. Tal iluminação não resulta de duas esferas separadas que se tocam de fora, assim como a alma move o corpo, em uma concepção dicotômica. O ser, ao contrário, não é substância imaterial, e sim, a possibilidade de algo se mostrar de determinado modo, de algo vir a ter existência. Esse algo é o ente, que só tem existência na rede humana de significados e sentidos.

Podemos, então, compreender o corpo como a dimensão do ser humano pela qual o ser nele se manifesta. A abertura do homem ao ser se dá pela corporeidade, pelo corporar. Embora não seja como os outros entes, não seria também o corpo a dimensão do ente do homem? O homem se diferencia dos outros entes por dar sentido e significado ao mundo que o circunda na relação com os outros homens e com as coisas, mas sua existência se configura com base na sua possibilidade de significar, de dar sentido e de criar o mundo (o mundo é um existencial, na compreensão de Heidegger). Não seria, então, o corpo a dimensão entitativa humana a partir da qual o ser se desvela? E nossos modos de ser e de estar situados no mundo - como passar, destinar-se à morte, viver nossa espacialidade, viver nossa sexualidade e ter experiência de linguagem -, não aconteceriam também somente através de nossa corporeidade?

\section{Considerações finais}

Retomando nossa discussão inicial acerca do modo como vivemos o corpo na contemporaneidade, indagamos: será que se trata de pensarmos sobre uma nova relação com o corpo? Ou ainda, será que os problemas que vivemos em relação ao corpo na nossa sociedade atual são meros problemas de corpo, como se pudéssemos tratá-los cindidamente, como se nada tivessem a ver com outros problemas contemporâneos? Acreditamos que não. $\mathrm{O}$ mesmo modo de pensar e de ser dominante na nossa era da técnica moderna é que faz com que, além de supervalorizarmos ou de negligenciarmos nosso corpo, também tomemos a natureza como reservatório de energia e a exploremos inescrupulosamente, tornando a Terra um local cada vez menos propício à vida. Esse mesmo modo de pensar e de ser também se consuma na legitimação da fome, da miséria e da guerra. Entre outras coisas, aceitamos calados e passivos a especulação do mercado de armas - negócio mais lucrativo do mundo capitalista - que lucra com a morte das pessoas. Cegamo-nos diante da exploração (muitas vezes escrava) da mão de obra. Como uma sociedade em que os interesses individuais e de pequenos grupos se sobressaem com tanta facilidade sobre os outros semelhantes e a natureza ao redor poderia ter outro tipo de relação com o próprio corpo?

Desde pequenos, o mundo, mesmo que não na forma de discurso assumido, mas muitas vezes nas entrelinhas de nossas relações, nos não ditos e na própria tradição filosófica ocidental, nos ensina que somos separados uns dos outros, que cada um é fundado 
em si mesmo e posto junto de outros, que as coisas que estão ao nosso redor são para usar e consumir. O corpo do outro também é colocado assim. A prostituição e a pornografia em nossa época são expressão disso. Temos um corpo e exploramos outro corpo, tomamo-lo como objeto de satisfação dos desejos do nosso corpo. Embora, é claro, a prostituição não tenha surgido na contemporaneidade, talvez nunca antes tenha atingido tamanha proporção. E a pedofilia? Como explicar que um adulto sinta atração por um corpo de criança? Seria uma disfunção da atração corporal, ou mais um problema de nossa época com inúmeras nuances em que a questão corporal está também envolvida de forma cindida?

O sentido desta reflexão é mostrar como perdemos nossa intimidade com o mundo e como vivemos com ele uma relação dicotômica. O corpo, restritamente vivido e considerado na dimensão de aparência para os outros e para o mundo, se põe no meio da dicotomia entre o eu, constituído a partir de mim mesmo, e um mundo que não me diz respeito, com existência exterior independente e desvinculada de mim. Entre o eu e o mundo/outros, existe um corte no qual se situa o corpo. Quando vivo com o meu corpo - minha dimensão entitativa - uma relação de ente externo, ou coisa externa, ele se torna apenas o que aparece de mim, o que mostro ao mundo; tem importância no nosso mundo atual como meio que manipulo para me mostrar sensual, competente ou confiável, por exemplo.

Não pretendemos, de forma alguma, encerrar a discussão sobre a corporeidade, deixando transparecer que a perspectiva na qual apoiamos nossa reflexão é a mais válida ou o único caminho de pensamento possível para repensarmos o corpo. Apenas tentamos apontar, com base na visão fenomenológicoexistencial, que nossa relação com o mundo pode ser repensada, no sentido de nos tornarmos, de verdade, pertencentes a ele, envolvidos e comprometidos com ele, daí a nossa tentativa de mostrar que temos com ele intimidade e familiaridade originárias. Precisamos, no entanto, resgatá-las para assumirmos responsabilidade com o mundo, de modo a não permitir que o individualismo se torne o modo hegemônico ou dominante de ser. 


\section{Rafael Auler de Almeida Prado}

Doutorando em Psicologia Clínica pela Universidade Católica de Pernambuco, Recife - PE - Brasil.

E-mail: rafaelpradoauler@gmail.com

\section{Marcus Tulio Caldas}

Doutor em Psicologia. Professor dos programas de graduação e pós-graduação em Psicologia Clínica da Universidade Católica de Pernambuco, Recife - PE - Brasil.

E-mail: marcus_tulio@uol.com.br

\section{Edilene Freire de Queiroz}

Doutora em Psicologia. Professora dos programas de graduação e pós-graduação em Psicologia Clínica da

Universidade Católica de Pernambuco

E-mail: equeiroz@unicap.br

\section{Endereço para envio de correspondência:}

Rua Benvinda de Farias, 449, apto 1001 Recife-PE. CEP: 51020-140

Recebido 15/09/2010, 1a Reformulação 02/11/2011, Aprovado 10/01/2012.

Aristóteles. (1969). Metafísica. (L. Vallandro, trad.). Porto Alegre: Globo

Critelli, D. M. (1996). Analítica do sentido. São Paulo: EDUC/ Brasiliense

Descartes, R. (2008). Discurso do método (P. Neves, trad.). Porto Alegre: L\&PM Pocket.

Heidegger, M. (2001). Seminários de Zollikon (G. Arnhold \& M. F. A. Prado, trads.). Petrópolis, RJ: Vozes.

Heidegger, M. (2006). Ensaios e conferências (3a. ed.; E. C. L. G. Fogel \& M. S. C. Schuback, trads.). Bragança Paulista, SP: Universitária São Francisco; Petrópolis, RJ: Vozes
Heidegger, M. (2008). Ser e tempo (3a. ed.; M. S. C. Schuback, trad.). Bragança Paulista, SP: Universitária São Francisco; Petrópolis, RJ: Vozes

Merleau-Ponty, M. (1999). Fenomenologia da percepção (2a. ed.; C. A. R. Moura, trad.). São Paulo: Martins Fontes.

Merleau-Ponty, M. (2007). O visível e o invisível (4a. ed., J. A. Gianotti \& A. M. Oliveira, trads.). São Paulo: Perspectiva

Michelazzo, J. C. (2003). Corpo e tempo. In Castro, D. S. P. de. (Org.). (pp.105-122). Corpo e existência. São Bernardo do Campo, SP: UNESP-FENPEC.

Platão. (1999). A República de Platão. (E. Corvisieri, trad.). São Paulo: Nova Cultural. (Coleção Os Pensadores) 